удк 343.3

B. С. Ишигеев

Байкальский государственный университет, г. Иркутск, Российская Федерация

Е. А. Гаврилов

Восточно-Сибирский институт МВД России, 2. Иркутск, Российская Федерация

С. В. Пясецкий

Восточно-Сибирский институт МВД России, г. Иркутск, Российская Федерация

\title{
ОБСТАНОВКА СОВЕРШЕНИЯ КОРЫСТНЫХ ПРЕСТУПЛЕНИЙ В РАЙОНАХ КРАЙНЕГО СЕВЕРА И МЕСТНОСТЯХ, ПРИРАВНЕННЫХ К НИМ
}

\begin{abstract}
АНнотАЦия. Исследуется один из важнейших структурных элементов криминалистической характеристики преступления - обстановка совершения преступления, значение которой трудно переоценить при расследовании практически всех преступлений, совершенных в условиях неочевидности, в том числе корыстной направленности. Раскрывается актуальность и значение изучения этой научной категории на примере расследования самых распространенных преступлений из числа постоянно регистрируемых - корыстных, т. е. посягающих на защищаемое государством право собственности. В статье дается общее определение обстановки, раскрывается такая дефиниция как «обстановка совершения преступления», указываются различные научные подходы к толкованию этого термина и проводится подробный анализ научных взглядов на понятие обстановки преступления, в частности, приводится научный взгляд, выражающий интегрированный подход $\mathrm{k}$ пониманию содержания обстановки. В статье учтен региональный аспект исследуемой проблемы и обозначена специфика влияния климатических и географических условий на характер совершения корыстных преступлений и их последующее расследование сотрудниками правоохранительных органов в районах Крайнего Севера и местностях, приравненных к ним.

кЛючЕВЫЕ словА. Криминалистика; криминалистическая методика; обстановка преступления; корыстные преступления; отдаленные районы Сибири.

ИНФОРМАЦИЯ О СТАТЬЕ. Дата поступления 1 октября 2016 г.; дата принятия к печати 23 октября 2016 г.; дата онлайн-размещения 30 ноября 2016 г.
\end{abstract}

V. S. Ishigeev Baikal State University, Irkutsk, Russian Federation

E. A. Gavrilov

East-Siberian Institute of MIA of Russia, Irkutsk, Russian Federation

S. V. Pyasetsky

East-Siberian Institute of MIA of Russia, Irkutsk, Russian Federation

\section{SITUATION OF COMMITTING MERCENARY CRIMES IN THE FAR NORTH REGIONS AND EQUIVALENT AREAS}

ABSTRACT. The authors of the present article study one of the most important structural elements of criminalistics characteristics of crime - the situation of committing a crime, the value of which cannot be overestimated in investigating practically all crimes committed in conditions of non-obviousness, including the mercenary ori-

(C) В. С. Ииигеев, Е. А. Гаврилов, С. В. Пясецкий, 2016

\section{Baikal Research Journal}


entation. The article reveals the topicality and significance of studying this scientific concept using the examples of investigating the most widely spread crimes of those to be registered constantly - the mercenary ones, that is, those that infringe the property right defended by the state. The article gives a general definition of the situation, reveals such a definition as a "a situation of committing a crime», points out to various scientific approaches to interpreting this term and carries out a detailed analysis of scientific viewpoints on the concept of the crime situation, in particular, presents a scientific viewpoint that expresses an integrated approach to understanding the content of the situation. The article takes into account the regional aspect of the problem being studied and marks the specifics of the impact of climatic and geographical conditions on the nature of committing mercenary crimes and their subsequent investigation by law enforcement officials in the Far North regions and the localities equated to them.

KEYWORDS. Criminalistics; criminalistics methods; crime situation; mercenary crimes; remote areas of Siberia.

ARTICLE INFO. Received October 1, 2016; accepted October 23, 2016; available online November 30, 2016.

Сибирь, являясь ресурсной кладовой России и всего мира, располагает крупными запасами углеводородного сырья, угля, урана, черных, цветных и драгоценных металлов, древесины, водных и гидроэнергетических ресурсов. Запасы угля составляют $80 \%$ общероссийских запасов, меди - $70 \%$, никеля - 68 \%, свинца $86 \%$, цинка - $77 \%$, молибдена - $82 \%$, золота - $41 \%$, металлов платиновой группы - 99 \%, гидроэнергетических ресурсов и запасов древесины - более 50 \% . Сибирь обладает значительным потенциалом эволюционного развития, особенно в черной и цветной металлургии, топливно-энергетическом комплексе и пищевой промышленности. Возможен быстрый рост в химии и нефтехимии, лесной и деревоперерабатывающей промышленности. Значительные резервы для роста имеют строительный и агропромышленный комплексы. Стратегической целью развития Сибири является обеспечение устойчивого повышения уровня и качества жизни населения на основе сбалансированной социально-экономической системы инновационного типа, гарантирующей национальную безопасность, динамичное развитие экономики и реализацию стратегических интересов России в мировом сообществе. Такой подход к формированию целей определяется необходимостью преодоления отставания развития социального сектора и превращения регионов Сибири в территорию комфортного проживания и успешного ведения бизнеса ${ }^{1}$.

Достижение поставленных на государственном уровне целей и задач по социально-экономическому развитию отдаленных регионов Сибири невозможно без надлежащей охраны конституционных прав и свобод граждан, защиты различных форм собственности, обеспечения общественной безопасности и общественного порядка, а также успешной борьбы с преступностью в рамках реализации основных направлений региональной уголовно-правовой политики государства.

Изучение преступности во взаимосвязи с социальной средой, экономическими, экологическими, социальными факторами способствует выявлению и прогнозированию неравномерности в состоянии и динамике преступности по регионам, что дает основание говорить о существовании территориальных особенностей преступности. Западными учеными данное направление в криминологии еще в XIX в. было названо «географией преступности» [1].

Изменения за последние годы, произошедшие во внешнеполитической и экономической сферах, резко изменили состояние преступности, особенно носящей

${ }^{1}$ Об утверждении Стратегии социально-экономического развития Сибири до 2020 года : распоряжение Правительства РФ от 5 июля 2010 г. № 1120-р (с изм. на 26 дек. 2014 г.) // СПС «КонсультантПлюс» .

\section{Baikal Research Journal}

электронный научный журнал Байкальского государственного университета 
корыстный характер. Здесь следует отметить, что региональная преступность зависит от состояния преступности в масштабах страны и обусловлена уровнем развития самой административной единицы, иначе говоря, местными факторами, которые характеризуют обстановку на исследуемой нами территории.

В научной литературе под термином «обстановка» (синонимы: «условие», «обстоятельство», «ситуация») понимается совокупность факторов, воздействующих на кого-либо или что-либо, создающих среду, в которой протекает что-либо. В словаре русского языка трактуется как положение, обстоятельства, условия существования кого-нибудь или чего-нибудь [2]. Юридическая наука выделяют такие виды обстановки, как криминологическая, криминогенная, оперативная, криминалистическая и др. Все они, безусловно, тесно связаны между собой, и провести подробный анализ одной из них невозможно, не соприкасаясь с другими. Познание криминологической и криминогенной составляющих необходимо для выработки стратегии и тактики борьбы с преступностью, а оперативная обстановка - это управленческое понятие, относящееся к области тактики непосредственной борьбы с преступностью, используемое в процессе организации, управления деятельностью органов внутренних дел.

Итак, криминологическая обстановка в отдаленных районах Сибири, как и в целом по России, в течение последних лет только осложняется. Определяющими факторами распространения преступности, в целом, выступают: экономический кризис в стране, вызванный дестабилизацией геополитической обстановки в контексте противостояния Россия - Запад, где немаловажное значение играют направленные на ослабление российской экономики санкции; отсутствие необходимого количества рабочих мест (безработица); отток квалифицированных кадров в наиболее перспективные регионы страны, низкий уровень доходов населения, который не способен обеспечить удовлетворение первичных потребностей человека (питание, одежда, жилье и т. д.); острая дифференциация между отдельными слоями населения по уровню доходов («бедные» и «богатые»); алкоголизация и наркотизация населения; активный приток иностранной дешевой рабочей силы, в частности, нелегальной, создающей конкуренцию местному населению, обусловленную желанием трудиться за низкую заработную плату, продолжающееся усиление миграционных процессов, связанных с предоставлением политического убежища иностранным гражданам, в том числе жителям Украины; проживание на территории региона значительного числа лиц, имеющих судимость.

Рассмотренные факторы оказывают, прежде всего, непосредственное воздействие на рост наиболее распространенного и опасного из всех видов преступности - корыстную. Обнищание населения на периферии стирает грани вседозволенности, ущемляет, провозглашенное Конституцией Российской Федерации право на защиту частной собственности добропорядочных и законопослушных граждан, провоцирует удовлетворение насущных материальных потребностей незаконными способами, в том числе путем совершения корыстных преступлений общеуголовной направленности.

Акцентирование внимания на корыстных преступлениях не перестает быть актуальным, так как именно они составляют значительную долю всех зарегистрированных преступлений в России. Так, половину всех зарегистрированных преступлений $(43,7 \%)$ в стране составляют хищения чужого имущества. Каждая четвертая кража, каждый двадцать первый грабеж, и каждое одиннадцатое разбойное нападение были сопряжены с незаконным проникновением в жилище, помещение или иное хранилище. Каждое тридцать второе зарегистрированное преступление - квартирная кража. Почти половина преступлений регистрируется в республиканских, краевых и областных центрах, пятая часть - в сельской

\section{Baikal Research Journal}


местности. Аналогичным образом ситуация складывается и в отдаленных районах Сибири. Так, только в Забайкальском крае за 6 месяцев 2016 г. совершено 8470 корыстных преступлений. Их доля от общего числа зарегистрированных преступных деяний составила 50,5\%. При этом приостановлены производством и остались не раскрытыми 5173 преступлений данных видов, или 75 \% от общего числа приостановленных. В местностях, приравненных к районам Крайнего Севера (Каларский и Тунгокочинский районы Забайкальского края) за 6 месяцев 2016 г. совершено 74 корыстных преступления общеуголовной направленности ${ }^{2}$.

В условиях сохраняющихся социальных противоречий, быстротечности экономических и политических процессов, усложнения механизма управления общественными и государственными институтами эффективность деятельности органов внутренних дел в значительной степени зависит от глубины и всесторонности комплексного анализа оперативной обстановки и своевременности реагирования на ее изменения.

Всякое преступление, в том числе и корыстное, как мы видим из представленного анализа оперативной обстановки, совершается в определенных пространственно-временных границах, а также под воздействием комплекса факторов, обусловливающих возможность его совершения. Комплекс указанных условий внешней среды, влияющих на совершение преступления, в научной криминалистической литературе принято именовать «обстановкой совершения преступления». Обстановка совершения преступления как место сосредоточения максимального количества его следов, приобретает характер одного из высоко информативных элементов криминалистической характеристики [3]. Вместе с тем вопросы, существующие в криминалистической науке по поводу такой научной категории как «криминалистическая характеристика преступлений», до сих пор не разрешены окончательно и требуют более внимательного и глубокого анализа [4].

В криминалистической литературе имеются различные подходы к пониманию обстановки преступления, различающиеся по объему рассматриваемого понятия.

Так, обстановку преступления иногда понимают как вещную обстановку места совершения преступления[5]. Однако, первое понятие значительно шире второго, поскольку включает в себя не только качественную характеристику совокупности объектов на месте происшествия, находящихся в различных связях и отношениях [6], но еще ряд условий, которые предшествуют, способствуют событию преступления и следуют за ним. На различие этих понятий обратил внимание еще в 1966 г. Р. С. Белкин [7].

Сам же Р. С. Белкин давал следующее определение «Обстановка происшествия или преступления - это конкретная жизненная ситуация. Она включает помимо материальной обстановки места происшествия также и другие элементы: поведение участников события, психологические отношения, возникающие между участниками события и т. п.» [7].

Другое определение дает В. А. Образцов. Он включает в это понятие «территориальную, климатическую, демографическую и иную специфику региона, в котором совершено преступление, а также обстоятельства, характеризующие непосредственно место, время, условия и другие особенности указанной жизненной ситуации» [8]. По мнению В. В. Тищенко, включение в обстановку характеристик региона слишком расширяет понимание данной категории [9].

В. И. Куликов под исследуемым нами понятием подразумевает «ограниченную пространственно-временными рамками конкретного события преступления систему материальных, социально-психологических элементов окружающей и

${ }^{2}$ Министерство внутренних дел Российской Федерации : офиц. сайт. URL: https://мвд.pф/ folder/101762/item/8306504/.

\section{Baikal Research Journal}

электронный научный журнал Байкальского государственного университета 
специально выбранной преступником среды, а иногда и некоторых его участников» [10]. Данное определение, на наш взгляд довольно абстрактно, так как не содержит указаний на конкретные взаимосвязи между ее элементами.

Н. П. Яблоков представляет обстановку как систему «различного рода взаимодействующих между собой до и в момент преступления объектов, явлений и процессов, характеризующих место, время, вещественные, природно-климатические, производственные, бытовые и иные условия окружающей среды, особенности поведения непрямых участников, противоправного события, психологические связи между ними и другие факторы объективной реальности, определяющие возможность, условия и иные обстоятельства совершения преступления» [11].

По нашему мнению, наиболее аргументировано и емко определение обстановки преступления рассматривал В. К. Гавло. Во-первых, он предлагал употреблять интегральное понятие «обстановка преступления» для обозначения в целом системы условий и обстоятельств, локализуемых в пространстве и во времени, материальной обстановки места происшествия, объекта посягательства, субъекта преступления и иных компонентов, связанных с подготовкой, совершением и сокрытием преступления; во-вторых, применительно к развитию этапов преступной деятельности субъекта в окружающей среде употреблять дифференцированное понятие обстановки преступления, расчленив ее на три самостоятельных и в то же время взаимосвязанных звена: «обстановка, предшествующая совершению преступления», «обстановка совершения преступления» и «обстановка, сложившаяся после совершения преступления» [12].

Оценка субъектом обстановки, в которой ему предстоит действовать, во многом предопределяет выбор способа совершения и сокрытия преступления, используемых орудий и средств [10].

При планировании преступления лицо оценивает обстановку, выясняет и анализирует условия, благоприятствующие или препятствующие реализации его замысла. Поскольку условия, в которых находится интересующий преступника объект, динамичный в той или иной степени, он стремится подобрать подходящие для осуществления его замысла наиболее благоприятные условия. Так, при разработке разбойного нападения на магазин преступник учитывает место его нахождения, возможность скрытного подхода, наличия или отсутствия охраны, время, когда в магазине меньше всего покупателей, когда накоплена максимальная выручка и др. Кроме того, бывают случаи, когда преступник самостоятельно активно стремится изменить обстановку, создать такие условия, которые способствовали бы осуществлению его преступного замысла и сокрытию совершенного преступления. Так, преступник с этой целью, может перед нападением на объект, закрыть объектив камер наружного наблюдения, войти в доверие к определенным лицам, в том числе к сотрудникам правоохранительных органов.

Выявление и изобличение преступника, подготавливающего, совершающего или совершившего корыстное преступление невозможно без учета основных особенностей условий жизни в том или ином районе. Это необходимо иметь в виду при организации работы правоохранительных органов в районах Сибири [13]. Соглашаясь с мнением В. А. Образцова о включении в понятие обстановки преступления элементов территориальной, климатической и демографической специфики региона, мы полагаем целесообразным выделить в качестве необходимых компонентов, входящих в структуру обстановки корыстного преступления, особенности географического положения, климатические условия, а также специфику населения отдаленных районов Сибири. К ним относятся: обширность территории, зачастую превышающая сотни километров, суровый континентальный климат (низкие зимние температуры, сильные ветры, снежные заносы, наводнения), не-

\section{Baikal Research Journal}

электронный научный журнал Байкальского государственного университета 
проходимая тайга и т. д. Перечисленные условия приводят в несвоевременному поступлению информации о совершенном преступлении, а также к объективной невозможности немедленного выезда на место происшествия сотрудников правоохранительных органов (дежурной следственно-оперативной группы), что также непосредственно характеризует обстановку, сложившуюся после совершения преступления и затрудняет установление лица его совершившего.

Кроме того, существенно сказывается на получении своевременной и надежной информации о преступлениях плотность населения в отдаленных районах Сибири. Малая плотность населения в отдаленных районах не дает возможности своевременно обнаружить даже реализованный преступный замысел. Эта особенность существенно затрудняет следственную и оперативную работу органов внутренних дел.

Также для отдаленных районов Сибири характерен своеобразный социальный и качественный состав населения. По сравнению с другими районами число лиц, ранее совершавших преступления, а также страдающих алкоголизмом, составляет значительную часть населения.

Так, в первом полугодии 2016 г. (в сравнении с аналогичным периодом прошлого года) в Забайкальском крае отмечался рост преступлений, совершенных лицами, ранее совершавшими преступления на 15,1 \% (с 5038 до 5797), удельный вес от расследованных преступлений составил $62,2 \%$.

В тот же период времени был зафиксирован рост на 29,4 \% (с 3269 до 4231) преступлений, совершенных в состоянии алкогольного опьянения, удельный вес от расследованных составил $45,4 \%$.

Таким образом, в структуру обстановки корыстного преступления, совершенного в отдаленных районах Сибири, целесообразно включить следующие элементы:

- временную и пространственную характеристику всех этапов события преступления;

- материальную обстановку мест подготовки, совершения и сокрытия преступления;

- погодные и иные природно-климатические условия;

- поведение участников события;

- социально-бытовые и психологические отношения между ними;

- условия общего характера, на фоне которого протекало преступное событие (общественное мероприятие и т. п.);

- обстоятельства, способствующие или препятствующие подготовке, совершению и сокрытию преступления.

Обстановка корыстного преступления, как мы видим, тесным образом связана со всеми элементами деятельности по совершению преступления и обладает специфическими особенностями. Знание обстановки преступления или хотя бы некоторых ее элементов позволяет следователю строить версии о преступнике, механизме преступления, а также целях и мотивах преступления.

\section{Список использованной литературы}

1. Чернов А. В. Криминогенная обстановка в Сибирском федеральном округе: Теория и практика уголовного права и уголовного процесса / А. В. Чернов. - Иркутск : Юрид. центр, 2006. - 266 с.

2. Ожегов С. И. Словарь русского языка / С. И. Ожегов, М. Ю. Шведова. - М. : Рус. язык, 1987. - 797 с.

3. Грибунов О. П. Обстановка совершения преступлений как ключевой элемент криминалистической характеристики преступлений, совершаемых на железнодорожном транспорте / О. П. Грибунов // Известия Тульского государственного университета. Экономические и юридические науки. - 2013. - № 5-2. - С. 59-63.

\section{Baikal Research Journal}


4. Гаврилов Е. А. Криминалистическая характеристика и ее соотношение с предметом доказывания / Е. А. Гаврилов // Деятельность правоохранительных органов в современных условиях : материалы XXI Междунар. науч.-практ. конф. Иркутск, 26-27 мая 2016 г. / отв. ред. Е. В. Рогова [и др.]. - Иркутск : Вос.-Сиб. ин-т МВД России, 2016. - С. 54-55.

5. Усманов У. А. Справочник следователя / У. А. Усманов. - М. : ПРИОР, 1998. — 256 с.

6. Белкин Р. С. Криминалистика. Общетеоретические проблемы : монография / Р. С. Белкин, А. И. Винберг. - М. : Юрид. лит., 1973. - 264 с.

7. Белкин Р. С. Собирание, исследование и оценка доказательств : монография / Р. С. Белкин. - М. : Наука, 1966. - 295 с.

8. Образцов В. А. О криминалистической классификации преступлений / В. А. Образцов // Вопросы борьбы с преступностью. - М. : Юрид. лит., 1980. - Вып. 33. - С. 90-98.

9. Тищенко В. В. Корыстно-насильственные преступления: криминалистический анализ : монография / В. В. Тищенко. - Одесса : Юрид. лит., 2002. - 390 с.

10. Куликов В. И. Основы криминалистической теории организованной преступной деятельности : монография / В. И. Куликов. - Ульяновск : Фил. Моск. гос. ун-та, 1994. - 256 с.

11. Криминалистика : учебник / отв. ред. Н. П. Яблоков. - М. : Юристъ, 1999. - 780 с.

12. Гавло В. К. Обстановка преступления как структурный компонент криминалистической характеристики преступления / В. К. Гавло // Проблемы совершенствования тактики и методики расследования преступлений : сб. науч. тр. - Иркутск : Иркут. гос. ун-т, 1980. - С. 51-53.

13. Броун А. П. Организация расследования преступлений в районах Сибири и Дальнего Востока с интенсивным экономическим развитием : учеб. пособие / А. П. Броун, В. М. Быков. - Омск : Ом. высш. шк. милиции МВД СССР, 1980. - 68 с.

\section{References}

1. Chernov A. V. Kriminogennaya obstanovka $v$ Sibirskom federal'nom okruge: Teoriya $i$ praktika ugolovnogo prava $i$ ugolovnogo protsessa [Criminogenic situation in the Siberian Federal District: theory and practice of criminal law and criminal procedure]. Irkutsk, Yuridicheskii tsentr Publ., 2006. 266 p.

2. Ozhegov S. I., Shvedova M. Yu. Slovar russkogo yazyka [Dictionary of the Russian Language]. Moscow, Russkii yazyk Publ., 1987. 797 p.

3. Gribunov O. P. Crime situation as a key element of criminalistics characteristic of crimes committed on the railway transport. Izvestiya Tul'skogo gosudarstvennogo universiteta. Ekonomicheskie $i$ yuridicheskie nauki = Bulletin of Tula State University. Economic and Legal Sciences, 2013, no. 5-2, pp. 59-63. (In Russian).

4. Gavrilov E. A. Criminalistics characteristic and its correlation with the fact in issue. In Rogova E. V. et al. (eds). Deyatel'nost' pravookhranitel'nykh organov $v$ sovremennykh usloviyakh. Materialy XXI Mezhdunarodnoi nauchno-prakticheskoi konferentsii. Irkutsk, 26-27 maya 2016 [Activity of law enforcement bodies in the current context. Materials of the 21st International Research Conference. Irkutsk, May 26-27, 2016]. Irkutsk, East Siberian Institute of the Ministry of Internal Affairs of Russia Publ., 2016, pp. 54-55. (In Russian).

5. Usmanov U. A. Spravochnik sledovatelya [Reference Book for Investigator]. Moscow, PRIOR Publ., 1998. 256 p.

6. Belkin R. S., Vinberg A. I. Kriminalistika. Obshcheteoreticheskie problemy [Criminalistics. General theoretical problems]. Moscow, Yuridicheskaya Literature Publ., 1973. 264 p.

7. Belkin R. S. Sobiranie, issledovanie i otsenka dokazatel'stv [Collecting, investigating and assessing evidences]. Moscow, Nauka Publ., 1966. 295 p.

8. Obraztsov V. A. On criminalistics classification of crimes. Voprosy bor'by s prestupnost'yu [Issues of fight against criminality]. Moscow, Yuridicheskaya Literature Publ., 1980, iss. 33, pp. 90-98. (In Russian).

9. Tishchenko V. V. Korystno-nasil'stvennye prestupleniya: kriminalisticheskii analiz [Mercenary-violent crimes: criminalistics analysis]. Odessa, Yuridicheskaya Literature Publ., 2002. 390 p.

10. Kulikov V. I. Osnovy kriminalisticheskoi teorii organizovannoi prestupnoi deyatel'nosti [Basics of criminalistics theory of organized criminal activity]. Ul'yanovsk, Branch of Lomonosov Moscow State University Publ., 1994. 256 p.

\section{Baikal Research Journal}


11. Yablokov N. P. (ed.). Kriminalistika [Criminalistics]. Moscow, Publ., 1999. 780 p.

12. Gavlo V. K. Situation of the crime as a structural component of criminalistics characteristic of the crime. Problemy sovershenstvovaniya taktiki i metodiki rassledovaniya prestuplenii [Problems of improving tactics and methods of investigating crimes]. Irkutsk State University Publ., 1980, pp. 51-53. (In Russian).

13. Broun A. P., Bykov. V. M. Organizatsiya rassledovaniya prestuplenii $v$ raionakh $\mathrm{Si}_{\text {- }}$ biri i Dal'nego Vostoka s intensivnym ekonomicheskim razvitiem [Organizing investigations of crimes in regions of Siberia and the Far East with intensive economic development]. Omsk Higher School of Militia, Ministry of Internal Affairs of the USSR Publ., 1980. 68 p.

\section{Информация об авторах}

Ишигеев Владимир Степанович - доктор юридических наук, профессор, кафедра уголовного права, криминологии и уголовного процесса, Байкальский государственный университет, 664003, г. Иркутск, ул. Ленина, 11.

Гаврилов Евгений Александрович - адъюнкт, майор полиции, Восточно-Сибирский институт МВД России, 664074, г. Иркутск, ул. Лермонтова, 110, e-mail: crim.lift@mail.ru.

Пясецкий Станислав Валерьевич - адъюнкт, подполковник внутренней службы, Восточно-Сибирский институт МВД России, 664074, г. Иркутск, ул. Лермонтова, 110, e-mail: stas_and_stas@mail.ru.

\section{Authors}

Vladimir S. Ishigeev - Doctor habil. (Law), Professor, Chair of of Criminal Law, Criminology and Criminal Procedure, Baikal State University, 11 Lenin St., 664003, Irkutsk, Russian Federation.

Evgeniy A. Gavrilov - Adjunct, Major of Police, East-Siberian Institute of the Russia's Interior Affairs Ministry, 110 Lermontov St., 664074, Irkutsk, Russian Federation; e-mail: crim.lift@mail.ru.

Stanislav V. Pyasetsky - Adjunct, Lieutenant-Colonel of Internal Service, East Siberian Institute of the Russia's Interior Affairs Ministry, 110 Lermontov St., 664074, Irkutsk, Russian Federation; e-mail: stas_and_stas@mail.ru.

\section{Библиографическое описание статьи}

Ишигеев В. С. Обстановка совершения корыстных преступлений в районах Крайнего Севера и местностях, приравненных к ним / В. С. Ишигеев, Е. А. Гаврилов, С. В. Пясецкий // Baikal Research Journal. — 2016. — T. 7, № 6. — DOI: 10.17150/2411-6262.2016.7(6).16.

\section{Reference to article}

Ishigeev V. S., Gavrilov E. A., Pyasetsky S. V. Situation of committing mercenary crimes in the Far North regions and equivalent areas. Baikal Research Journal, 2016, vol. 7, no. 6. DOI: 10.17150/2411-6262.2016.7(6).16. (In Russian).

\section{Baikal Research Journal}

